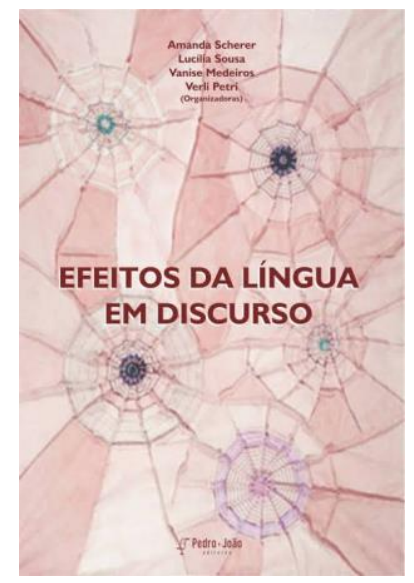

\title{
Efeitos da língua em discurso ${ }^{1}$ \\ Effects of language on speech
}

Ana Paula Correa ${ }^{2}$

ORCID: https://orcid.org/0000-0002-0993-0090

Andressa Brenner ${ }^{3}$

ORCID: https://orcid.org/0000-0002-9335-4849

Bruna Cielo ${ }^{4}$

ORCID: https://orcid.org/0000-0003-1313-238X

Denise Machado Pinto 5

ORCID: https://orcid.org/0000-0003-4901-5601

Resumo:Efeitos da Língua em Discurso, organizado pelas professoras pesquisadoras Amanda Scherer, Lucília Souza, Vanise Medeiros e Verli Petri, é um livro fruto da parceria entre o Laboratório Arquivos do Sujeito (UFF), o Laboratório Corpus (UFSM) e o E-1@ dis - Laboratório Discursivo do Sujeito (USP). Ao longo de dezesseis artigos divididos em quatro partes, o leitor pode desfrutar de pesquisas que tomam a língua como arquivo pelo viés discursivo da Análise de Discurso. O resultado é uma obra pulsante que proporciona olhares sobre a língua em rede, seja na mídia ou em documentos oficiais; enquanto um saber institucionalizado, uma memória ou ainda uma materialidade constituída de espessura política.

Palavras-chaves: língua; discurso; Análise de Discurso; História das Ideias Linguísticas.

Abstract: Efeitos da Lingua em Discurso, organized by the research professors Amanda Scherer, Lucília Souza, Vanise Medeiros and Verli Petri, is a book that resulted from a partnership between Laboratório Arquivos do Sujeito (UFF), Laboratório Corpus (UFSM) and E-1@ dis - Laboratório Discursivo do Sujeito (USP). Throughout sixteen articles divided into four parts, the reader can enjoy researches that take the language as a archive by the discursive theory from the Discourse Analysis. The result is a pulsating work that provides glimpses over the language as a networked, whether in the media or in official documents; as an institutionalized knowledge, a memory or even a materiality constituted of a political issue

Keywords: language; speech; Discourse Analysis; History of Linguistic Ideas.

\footnotetext{
${ }^{1}$ O presente trabalho foi realizado com apoio da Coordenação de Aperfeiçoamento de Pessoal de Nível Superior - Brasil (CAPES) - Código de Financiamento 001.

${ }^{2}$ Doutoranda do Programa de Pós-Graduação em Letras, Área de Concentração em Estudos Linguísticos, da Universidade Federal de Santa Maria - UFSM. E-mail: anapaulaalvescorrea@ gmail.com.

${ }^{3}$ Doutoranda do Programa de Pós-Graduação em Letras, Área de Concentração em Estudos Linguísticos, da Universidade Federal de Santa Maria - UFSM e bolsista CAPES - Programa de Demanda Social (DS). E-mail: andressabfernandes93@gmail.com.

${ }^{4}$ Doutoranda do Programa de Pós-Graduação em Letras, Área de Concentração em Estudos Linguísticos, da Universidade Federal de Santa Maria - UFSM e bolsista CAPES - Programa de Demanda Social (DS). E-mail: bruna.cielo.c@gmail.com.

${ }^{5}$ Doutoranda do Programa de Pós-Graduação em Letras, Área de Concentração em Estudos Linguísticos, da Universidade Federal de Santa Maria - UFSM e bolsista CAPES - Programa de Demanda Social (DS).. E-mail: dnisemachado@gmail.com.
} 
Efeitos da Língua em Discurso, organizado pelas professoras pesquisadoras Amanda Scherer, Lucília Souza, Vanise Medeiros e Verli Petri, apresenta-se como um livro pulsante, originário de uma rede de cooperação, conhecimento e afeto entre o Laboratório Arquivos do Sujeito (UFF), o Laboratório Corpus (UFSM) e o E-1@ dis Laboratório Discursivo do Sujeito (USP). Ancorado no campo teórico da Análise de Discurso de linha francesa trabalhada com fôlego no Brasil, o livro enlaça artigos a partir de uma estruturação em quatro partes: língua em redes; saberes sobre a língua; língua, memórias em curso; o político na língua. Como indica a inscrição de contracapa, trata-se de uma construção enquanto "manifesto científico", um gesto político preciso que nos oportuniza o contato com reflexões feitas a partir de projetos realizados por pesquisadores que tomam a língua pelo viés discursivo.

A série de textos alocados na primeira parte, "Língua em redes", inicia-se com o artigo instigante de Régine Robin traduzido por Thiago Mattos, Do corpo ciborgue ao estágio da tela: as novas fronteiras, que se debruça sobre quatro reflexões: o apagamento das fronteiras do corpo, o apagamento das fronteiras entre o real e o universo da simulação, a fragilização das fronteiras entre autor e leitor e o apagamento das fronteiras entre o verdadeiro e o falso, o passado e o presente, o passado e a imagem do passado. Imbricando materialidades cinematográficas, literárias, midiáticas, virtuais e históricas, a autora disserta sobre a entrada ou a simples existência passiva de um sujeito da língua em um mundo que está sem fronteiras. Nas últimas linhas de escritura, jaz a afirmação de que estamos diante de um novo simbólico e de novas formas de laços sociais; algo que pode muito bem ser lido como uma incitação a novas perguntas. Em A memória e o valor do tempo: um enlace pelo discurso, Cristiane Dias, considerando o tempo em sua dimensão histórico-social, a saber, a memória do tempo, reflete acerca desta memória a partir da análise do valor do tempo. Nesse sentido, trazendo à baila a questão da globalização, condição de produção do discurso do tempo, contexto sócio-histórico-ideológico, afirma que o sentido do econômico vai se configurando como um aspecto fundamental para a compreensão da memória do tempo. Ainda na primeira parte do livro, em (Re)Significando a TV: apontamentos sobre a memória no discurso midiático, Silmara Dela Silva propõe uma discussão sobre o funcionamento da memória nos discursos da/na mídia. A autora, tendo como foco dizeres sobre a televisão em um anúncio em vídeo destinado à venda de um aparelho televisivo, com circulação na atualidade, objetiva conceber de que modo se constituem os sentidos para a televisão e para os sujeitos interpelados à condição de consumidores nesses dizeres. 
Já na segunda parte do livro, "Saberes sobre língua”, José Horta Nunes, com seu texto $O$ dicionário do dialeto caipiracicabano: uma gramatização na cidade, apresenta uma análise discursiva da última edição do Dicionário do Dialeto Caipiracicabano, com o objetivo de mostrar de que modo a língua e o espaço-tempo em que se inserem os sujeitos falantes são significados. Sua análise revela que a dicionarização regional, no final do século XX e início do século XXI, produz uma outra imagem dos sujeitos e da língua, que se distingue do estereótipo do caipira rural, assim como da imagem do dialeto caipira como compreendida na primeira metade do século XX. Vanise Medeiros, em Saberes sobre língua e sujeito: o glossário pelo literato, traz uma reflexão de saberes sobre a língua constituídos pelo sujeito literato, a partir do glossário do escritor Mário Palmério, considerando o fazer literário como: saber sobre a língua; memória da e na língua; inscrição do sujeito na língua. Em síntese, a autora mostra que o glossário em questão é escrito por um literato que se coloca na posição de lexicógrafo e, nele, se pode observar uma oposição entre rural x urbano que se acentua no léxico e na oralidade rústica e original que se quer capturar - o que o caracteriza como um glossário para o povo pretendendo-se nacional. O texto que se segue é de autoria de Lívia Letícia Belmiro Buscácio, intitulado de Mário de Andrade, um nome, um arquivo, um acontecimento, e propõe um olhar teórico embasado pelo enlace entre Análise de Discurso e História das Ideias Linguísticas para observar o funcionamento do nome de autor como um acontecimento discursivo. Analisando diversos tipos de materialidades, a autora apresenta uma análise da memória da (hiper)língua brasileira no tocante de efeitos de sentido produzidos nome de Mário de Andrade tanto no discurso sobre a língua portuguesa do/no Brasil quanto sobre a escritura literária.

Também nesta parte, em Relações discursivas entre espaço, sujeito e língua, Luiza Katia Castelo Branco traz à baila os resultados de sua pesquisa de doutoramento, em que se buscou compreender o imaginário de homogeneidade linguística em relação ao discurso da Comunidade dos Países de Língua Portuguesa (CPLP). Pensando as organizações internacionais como formas históricas de arranjo do espaço do direito em batimento com a forma histórica do sujeito de direito, o texto propõe uma análise da questão lusofônica perpassando e costurando a noção de política de línguas. O resultado é um texto denso que se encarrega de suscitar e responder questionamentos teóricos acerca de uma política de língua oficial que busca dar conta da língua(s) portuguesa(s) que se historiciza(m) de maneiras diferentes. O artigo Colégio Pedro II, francês e disciplinarização: memória da/na língua francesa na constituição de um campo 
disciplinar escolar no Brasil, escrito por Felipe Barbosa Dezerto, apresenta uma pesquisa fruto de seu doutorado, no qual objetivou analisar como se constitui a disciplinarização da língua francesa enquanto campo disciplinar nomeado francês, após a fundação do Colégio Pedro II, em 1837. Para tanto, o autor filia-se à Análise de Discurso e à História das Ideias Linguísticas e parte para a construção de um corpus empírico que dá conta de instrumentos linguísticos (programas e livros didáticos) de três períodos vivenciados pelo Colégio Pedro II: sua fundação enquanto instituição de ensino, o início da república no Brasil e a era varguista. Ao tomar essas materialidades, autor passa a compreendê-los como fundamentais no processo de disciplinarização do francês e, com isso, conclui que a língua francesa fornece algum modelo cultural de um certo período na educação, algo que tem estreita relação com a noção de civilização dada meio de práticas pedagógicas. Ao final, Dezerto traça indagações que nos convidam a refletir sobre o possível deslocamento do padrão francês citado ao longo do artigo, para o norte-americano, e como essa mudança de paradigma na educação afeta-nos.

No referente à terceira parte da obra, "Língua, memórias em curso", essa é iniciada pelo texto Algumas reflexões sobre uma memória na e da língua..., de autoria de Amanda Eloina Scherer. Com uma escrita repleta de lembranças de tempos nostálgicos em Santa Maria, a autora nos apresenta parte de sua vida ao narrar seu(s) encontro(s) com a língua. Aqui, as memórias da analista mesclam-se à memória da língua produzindo o efeito de familiaridade daqueles que encontram nas letras, na língua, no sentido, na memória e na história o seu caminho de investigação, mas, ainda mais, o seu caminho da/na vida. Em Entre a memória e a atualidade: a determinação histórica dos estudos filológicos pelos saberes da linguística, Caroline Mallmann Schneiders sustenta que há uma determinação histórica na constituição dos estudos filológicos que se dão a partir Serafim da Silva Neto, no Brasil, ao final do século XIX e início do XX. Para tanto, a autora apresenta um percurso construído em sua tese de doutorado que se ocupou em analisar como um domínio de memória da Linguística é retomado em uma filiação da Filologia. Trata-se de um artigo com bastante rigor teórico-metodológico, em que nos é apresentado um arquivo de pesquisa, que compõe um corpus, para, por fim, constituir dois recortes discursivos que são analisados, mobilizando noções como citação, paráfrase discursiva e discursivotransverso.

A seguir, temos o artigo Língua: o patrimônio que nos une de Larissa Montagner Cervo, o qual trata da relação patrimônio, língua e sujeito. A reflexão proposta desenvolveu-se a partir da significação da Língua enquanto objeto do Museu da Língua 
Portuguesa, de modo que a autora problematiza o conceito de político e o modo como o sujeito é dito e referenciado nessas condições de produção. Trata-se de um estudo que nos leva a refletir sobre o que é valioso para nós em se tratando de língua, bem como sobre o que seria pertencer a língua que se fala. Querer dizer, saber dizer, escrito por Lauro José Siqueira Baldini e Valéria Regina Ayres Motta, traz à baila, sob uma perspectiva que toma a teoria discursiva pecheuxtiana, em relação com a psicanálise e a história, uma questão de desejo e imaginário presentes no ensino-aprendizagem de uma língua estrangeira, mais especificamente, da língua inglesa. O objetivo é, portanto, construir reflexões a partir da forma como o aluno de um curso de Letras compreende o seu lugar e a sua língua materna em relação à “nova língua-a-saber". São observados a presença de pré-construídos que partem de um desejo de completude posta em imaginários sobre o inglês como uma língua de negócios, ou ainda, uma língua da globalização. Por fim, os autores concluem que esse aluno - professor em formação - não poderia estar senão em uma relação de prazer e angústia ao se significar nessa outra língua, algo que faz desvelar o real da língua, o qual se mostra inatingível. Para encerrar a parte três do livro, somos contemplados com Línguas e memórias: o jogo significante em composições musicais brasileiras, de Thalita Miranda Gonçalves Sampaio e Eliana de Almeida. Trata-se de um artigo que, entre as tensões de uma língua do Outro na sintaxe da língua portuguesa falada no Brasil, trabalha sentidos sobre a língua e a relação com o sujeito nacional através de um corpus artístico. Para tanto, músicas de Noel Rosa, Chico Buarque e Zeca Baleiro são tomadas para análise em um movimento de busca que observa marcas de empréstimos e estrangeirismos em seu funcionamento discursivo. Tudo isso, considerando as condições de produção distintas, que afirmam uma língua marcada pela incompletude, pelo efeito metafórico, uma vez que heterogênea. Ao final, as autoras concluem que existe uma relação de contradição e de memória dada pela língua portuguesa, a qual faz significar outras línguas não nacionais através de palavras estrangeiras.

Por fim, a quarta parte do livro, denominada “O político na Língua”, nos apresenta Um anjo torto me disse: o acontecimento acordooooooooooooooooôôô, de Lucília Maria Abrahão e Sousa. O artigo nos remonta a primeiro de julho de 2013, data em que ocorria o jogo futebolístico que marcava a final da Copa das Confederações, no Maracanã, no Rio de Janeiro. O momento sócio-histórico estava carregado de protestos e atos públicos em várias cidades, inclusive aos arredores do próprio estádio. Outrossim, a primeira reflexão desencadeada diz respeito aos efeitos da memória discursiva no que se refere a 
grandes copas mundiais de futebol, isto é, a exaltação do povo em relação a seleção brasileira e ao Brasil, enquanto "país do futebol". A análise proposta pela autora toma como objeto o enunciado entoado pelos torcedores quando, em pouco mais de três minutos, Fred faz o primeiro gol, de forma bastante improvável, a saber: caído, tombado na grande área, de forma bastante ágil, assemelhando-se a um anjo torto, desafiando as leis da gravidade, eis, então, a razão para o título deste artigo. A torcida, embora sem entender como o lance obteve êxito, comemorou e, um tempo depois, entoou o mesmo enunciado dos manifestantes que cortavam a paisagem com cartazes e faixas com questões de governabilidade, estrutura, investimentos e corrupção. A reflexão, a partir do enunciado, está pautada na noção de acontecimento discursivo e nos leva ao encontro do movimento de sentidos dentro do campo esportivo, que é da ordem do político, rompendo com o trajeto do repetível. Ainda nesta parte, temos Manifestação na língua e no dicionário: movimentos de sentido, de Verli Petri. $\mathrm{O}$ artigo traz à baila os sentidos da palavra manifestação na atualidade da Língua e os sentidos que o verbete manifestação carrega no dicionário. A análise proposta pela autora nos leva ao entendimento de que a língua está sempre em pleno funcionamento, aberta ao deslize, ao movimento de sentidos, em relação com história e memória. Já no artigo de fechamento do livro, Efeitos de feminismo e mulher na marcha das vadias: a escrita do corpo, a autora Dantielli Assumpção Garcia analisa a campanha Meu feminismo é..., produzida pela Marcha das Vadias de Ouro Preto e divulgada na plataforma digital Facebook. Garcia objetiva analisar a formulação dos sentidos relacionados ao feminismo e reflete também sobre o corpo como forma de materializar um discurso de resistência em oposição ao discurso da violência. Além disso, existe um enfoque no ciberespaço e nas redes sociais enquanto lugares que fazem circular os sentidos produzidos sobre a posição da mulher na contemporaneidade, o feminismo e a militância pela causa feminina/feminista.

Assim, encerra-se uma coletânea genial, organizada com carinho, com resistência e com luta. Contudo, os sentidos suscitados por esses textos não se fecham ao virarmos a última página, pois o manifesto científico segue suscitando aos leitores refletir sobre a língua e questionar sobre o discurso; quiçá, como postulou Pêcheux, ousar se revoltar.

\section{Referências}

SCHERER, A.; SOUSA, L.; MEDEIROS, V.; PETRI, V. Efeitos da língua em discurso. São Carlos: Pedro \& João Editores, 2019, 263 p. 


\section{Para citar essa obra:}

CORREA, Ana Paula et al. Efeitos da língua em discurso In: RUA [online]. Volume 25, número 2 - p. 593-598 - e-ISSN 2179-9911 - novembro/2019. Consultada no Portal Labeurb - Revista do Laboratório de Estudos Urbanos do Núcleo de Desenvolvimento da Criatividade. http://www.labeurb.unicamp.br/rua/

Capa: primeira capa do livro "Efeitos da língua em discurso"

\section{Laboratório de Estudos Urbanos - LABEURB}

Núcleo de Desenvolvimento da Criatividade - NUDECRI

Universidade Estadual de Campinas - UNICAMP

http://www.labeurb.unicamp.br/

Endereço:

LABEURB - LABORATÓRIO DE ESTUDOS URBANOS

UNICAMP/COCEN / NUDECRI

CAIXA POSTAL 6166

Campinas/SP - Brasil

CEP 13083-892

Fone/ Fax: (19) 3521-7900

Contato: http://www.labeurb.unicamp.br/contato 